\title{
Hemorrhagic Shock
}

National Cancer Institute

\section{Source}

National Cancer Institute. Hemorrhagic Shock. NCI Thesaurus. Code C35017.

Hypoperfusion of body tissues due to acute blood loss, resulting in cellular injury and vital organ dysfunction. 